\title{
The effect of some antiseptic drugs on the energy transfer in chromatophore photosynthetic membranes of purple non-sulfur bacteria Rhodobacter sphaeroides
}

\author{
Marina G. Strakhovskaya ${ }^{1,2}$ (D) Eugene P. Lukashev ${ }^{1} \cdot$ Boris N. Korvatovskiy ${ }^{1} \cdot$ Ekaterina G. Kholina $^{1}$. \\ Nuranija Kh. Seifullina ${ }^{1} \cdot$ Peter P. Knox ${ }^{1} \cdot$ Vladimir Z. Paschenko $^{1}$
}

Received: 24 August 2020 / Accepted: 24 November 2020 / Published online: 2 January 2021

(c) Springer Nature B.V. 2021

\begin{abstract}
Chromatophores of purple non-sulfur bacteria (PNSB) are invaginations of the cytoplasmic membrane that contain a relatively simple system of light-harvesting protein-pigment complexes, a photosynthetic reaction center (RC), a cytochrome complex, and ATP synthase, which transform light energy into the energy of synthesized ATP. The high content of negatively charged phosphatidylglycerol (PG) and cardiolipin (CL) in PNSB chromatophore membranes makes these structures potential targets that bind cationic antiseptics. We used the methods of stationary and kinetic fluorescence spectroscopy to study the effect of some cationic antiseptics (chlorhexidine, picloxydine, miramistin, and octenidine at concentrations up to $100 \mu \mathrm{M}$ ) on the spectral and kinetic characteristics of the components of the photosynthetic apparatus of Rhodobacter sphaeroides chromatophores. Here we present the experimental data on the reduced efficiency of light energy conversion in the chromatophore membranes isolated from the photosynthetic bacterium $R b$. sphaeroides in the presence of cationic antiseptics. The addition of antiseptics did not affect the energy transfer between the light-harvesting LH1 complex and reaction center (RC). However, it significantly reduced the efficiency of the interaction between the LH2 and LH1 complexes. The effect was maximal with $100 \mu \mathrm{M}$ octenidine. It has been proved that molecules of cationic antiseptics, which apparently bind to the heads of negatively charged cardiolipin molecules located in the rings of light-harvesting pigments on the cytoplasmic surface of the chromatophores, can disturb the optimal conditions for efficient energy migration in chromatophore membranes.
\end{abstract}

Keywords Chromatophores $\cdot$ Light-harvesting complexes $\cdot$ Energy transfer $\cdot$ Rhodobacter sphaeroides $\cdot$ Antiseptics

\section{Introduction}

Purple non-sulfur bacteria (PNSB) are facultative aerobic gram-negative bacteria that use organic compounds as electron donors for anoxigenic photosynthesis (McEwan 1994). Chromatophores of purple bacteria are invaginations of the cytoplasmic membrane that contain a relatively simple system of light-harvesting protein-pigment complexes, a photosynthetic reaction center (RC), a cytochrome complex, and

Marina G. Strakhovskaya

maristra@yandex.ru

1 Biophysics Department, Faculty of Biology, Lomonosov Moscow State University, Moscow, Russia 119234

2 Federal Scientific and Clinical Center of Specialized Types of Medical Care and Medical Technologies of the Federal Medical and Biological Agency of Russia, Moscow, Russian Federation
ATP synthase, which transform light energy into the energy of synthesized ATP.

In Rhodobacter sphaeroides ( $R b$. sphaeroides), chromatophores isolated from cells are spherical particles $\sim 70 \mathrm{~nm}$ in diameter (Sener et al. 2007). The protein components of the chromatophores (light-harvesting chlorophyll-protein complexes LH2 and LH1) are responsible for efficient absorption of light; RC and the cytochrome complex bc1, for the primary photochemical processes; ATP synthase, for the synthesis of ATP. In particular, according to Cartron et al. (2014), the chromatophore particle of $R b$. sphaeroides bacteria growing phototrophically under specific conditions contains 24 protein-pigment complexes of RC, 24 LH1 complexes of the core antenna surrounding RC proteins, $67 \mathrm{LH} 2$ complexes of the peripheral antenna, eight cytochrome complexes $b c_{1}$, and two ATP synthase molecules. $R b$. sphaeroides chromatophores are known to contain a significant amount (42 mol\%) of negatively 
charged phospholipids-phosphatidylglycerols (PG) and cardiolipins (CL) (Nagatsuma et al. 2019). In purified LH1-RC complexes of $R b$. sphaeroides, the relative content of PG and CL increases to $90 \mathrm{~mol} \%$ : the LH1-RC complex of $R b$. sphaeroides is associated with $\sim 31$ molecules of phospholipids, including 17 negatively charged CL, 11 negatively charged PG, and 3 amphiphilic phosphatidylethanolamine (PE) molecules (Nagatsuma et al. 2019).

The thoroughly characterized photosynthetic membranes of PNSB as well as isolated RC are convenient systems for studying the influence of various external factors, among them phenols (Escher et al. 2001), herbicides (Kasuno et al. 2016), certain drugs (dipyridamole and a number of its derivatives) and chemical chaperones (alkylated hydroxybenzenes) (Knox et al. 2000, 2001, 2010). The functional parameters of the electron transfer chain are very sensitive to the structural and dynamic state of the transmembrane phototransforming complex, including the influence on its hydrogen bonds (McMahon et al. 1998; Kriegl et al. 2003; Goushcha et al. 2003; Krasilnikov et al. 2007). Changes in the functioning of this system can be detected directly using modern methods of absorption and fluorescence spectralkinetic analysis.

The high content of negatively charged PG and CL in PNSB chromatophore membranes makes these structures potentially sensitive to the cationic antimicrobials. Thus, cationic antiseptics readily bind to the negatively charged bacterial membranes, alter lateral diffusion coefficients of membrane lipids, affect lipid order parameters, and facilitate pore formation (Kholina et al. 2020). Cationic antimicrobial compounds such as disinfectants and antiseptics are used in large amounts for the prevention of infectious diseases. Their consumption has increased especially during the current COVID-19 pandemic (Baker et al. 2020; Opatz et al. 2020). After use these antimicrobials most often enter wastewaters (Kodama et al. 1988). PNSB live in muddy soil, waters rich in organic matter, sewage sludge (Okubo et al. 2006; Wei et al. 2016), and are a part of active sludge (Liang et al. 2009). That is, PNSB occupy places with a potential of disinfectants and antiseptics accumulation. However, the effect of cationic antiseptics on the photosynthetic membranes of PNSB is not known. In this work, we analyzed the effects of some widely used pharmaceutical preparations of cationic antiseptics on the spectral and kinetic characteristics of the components of the photosynthetic apparatus of $R b$. sphaeroides chromatophores. Special attention was paid to the study of energy migration in isolated chromatophores as well as the coupling between light harvesting complexes LH2 and LH1. The antiseptics studied in this work included biguanides-chlorhexidine digluconate and picloxydine dihydrochloride, the last in combination with the polysorbate 80 surfactant, and quaternary ammonium compounds
(QAC)—miramistin and octenidine, the last in combination with phenoxyethanol (Octenisept).

\section{Materials and methods}

Wild-type Rhodobacter sphaeroides bacteria were grown on Ormerod liquid culture medium (Pimenova et al. 1983) under anaerobic conditions in a luminostat at a temperature of about $30^{\circ} \mathrm{C}$ for 3 days. Ammonium malate or sodium malate was used as a source of carbohydrate. $10 \% \mathrm{NaOH}$ solution was added to the Ormerod medium to reach $\mathrm{pH}$ 6.8. Then, the Ormerod medium was sterilized for 40-60 min at 50,662.5 Pa. Before seeding, $0.5 \mathrm{ml}$ of concentrated yeast autolysate solution was added per $10 \mathrm{ml}$ of the medium.

Chromatophores were isolated from fresh cells in the 5-6-day culture. Before isolating, the cells were washed with sodium phosphate buffer (100 mM, pH 7.5). The standard method of fractional centrifugation after ultrasonic cell disintegration was applied (Michels and Konings 1978). The chromatophores were suspended in $50 \mathrm{mM}$ sodium phosphate buffer $(\mathrm{pH} 7.5)$ and stored at a temperature of $-20^{\circ} \mathrm{C}$.

Ready-made pharmaceutical preparations chlorhexidine digluconate $20 \%$, picloxydine dihydrochloride $0.05 \%$ (Vitabact), miramistin $0.01 \%$, and octenidine $0.1 \%$ (Octenisept) were diluted with distilled water to obtain antiseptic solutions with concentrations in the range of 5-100 $\mu \mathrm{M}$. Taking into account that Octenisept contains, in addition to octenidine, $2 \%$ phenoxyethanol, phenoxyethanol diluted with distilled water to $1-10 \mathrm{mM}$ was used as an additional control. Then chromatophores were added to samples with or without antiseptics. The measurements were performed after $10 \mathrm{~min}$ of chromatophore incubation at room temperature. The final concentration of chromatophores in the samples corresponded to $\sim 10 \mu \mathrm{M}$ of photoactive pigment.

The zeta potential of the chromatophores before and after the addition of antiseptics was measured with a Malvern Zetasizer Nano.

Absorption spectra were recorded with a modified Hitachi-557 spectrophotometer. Fluorescence emission and excitation spectra were obtained using a Fluorolog-3 fluorimeter (Horiba Jobin Yvon) equipped with an Osram XBO $450 \mathrm{~W}$ xenon arc lamp and Hamamatsu R5509 PMT detector. Emission spectra were recorded using excitation at $370 \mathrm{~nm}$. The slit widths of the emission and excitation monochromators were set to correspond to bandwidths of 2 and $5 \mathrm{~nm}$, respectively. For excitation spectra, the slit widths of the emission and excitation monochromators corresponded to bandwidths of 5 and $2 \mathrm{~nm}$, respectively. The fluorescence decay kinetic curves were measured with photon counting system at 860 and $890 \mathrm{~nm}$ (the fluorescence maxima of the LH2 and LH1, respectively) using Becker \& Hickl equipment. The instrument function of the recording 
system was 30 ps. A Tema-150 femtosecond laser system (Avesta-Project LLC, Russia) was used as a source of exciting light. It generated 300-fs light pulses at $525 \mathrm{~nm}$ (repetition frequency, $80 \mathrm{MHz}$; average radiation power, $2.8 \mathrm{~W}$; single pulse energy, $34 \mathrm{~nJ}$ ). In the experiments, the energy of the exciting light pulses was reduced using neutral light filters to a level determined by the sensitivity of the recording system. The average radiation power density was $3 \times 10^{-4} \mathrm{~W} /$ $\mathrm{cm}^{2}$. The fluorescence kinetics was approximated using the two exponential fitting. The decay times $\tau$ were calculated using a least squares fitting algorithm taking into account the instrument response function $30 \mathrm{ps}$.

\section{Results}

Figure 1 shows the absorbance and fluorescence spectra of Rb. sphaeroides chromatophore preparations. The main components of the absorbance spectrum (Fig. 1, curve 1) are: the Soret band of bacteriochlorophylls (BChls) with a maximum at $370 \mathrm{~nm}$, three absorption bands of carotenoids in the range $420-510 \mathrm{~nm}$, the $Q_{x}$ absorption band of BChls with a maximum at $\sim 590 \mathrm{~nm}$, the $\mathrm{Q}_{\mathrm{y}}$ absorption bands of the light-harvesting complex 2 (LH2) at 800 and $850 \mathrm{~nm}$, and the $\mathrm{Q}_{\mathrm{y}}$ absorption band of the LH1 complex recorded as a shoulder at $870 \mathrm{~nm}$. The low intensity contribution to the absorbance spectrum at $750 \mathrm{~nm}$ may be that of bacteriopheophytin (BPhe); according to (Trissl et al. 1999), it may also be associated with monomeric BChls contained in the chromatophore preparations. In the fluorescence spectrum (Fig. 1, curve 2), the main maximum near $880 \mathrm{~nm}$ is due to the fluorescence of the LH1 complex, to which the energy absorbed by all light-harvesting pigments ultimately drains. The shoulder at $\sim 850 \mathrm{~nm}$ is due to the fluorescence of the LH2 complex. A small contribution to the fluorescence

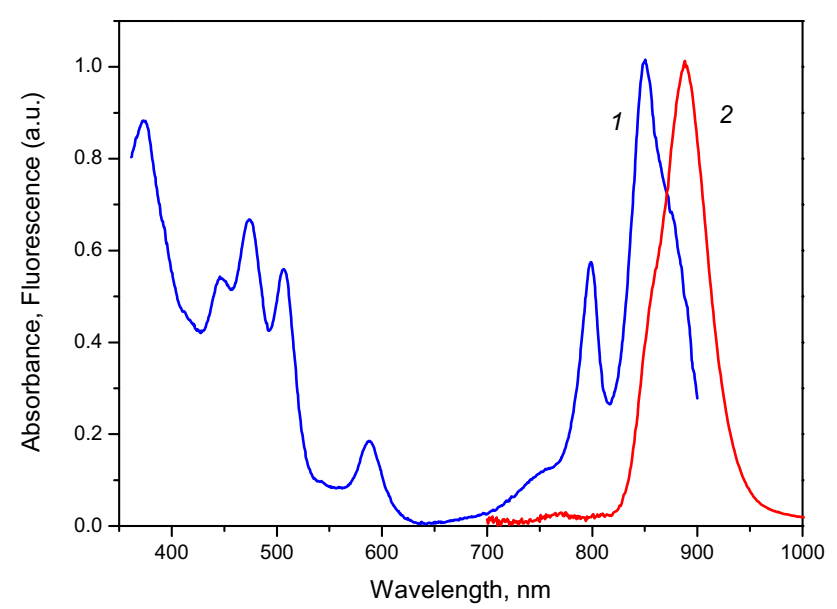

Fig. 1 Normalized absorbance (1) and fluorescence (2) spectra of $R b$. sphaeroides chromatophores spectrum of chromatophores at $\sim 770 \mathrm{~nm}$ is probably due to the fluorescence of BPhe and monomeric BChl absorbing at $750 \mathrm{~nm}$.

Chromatophores in control samples had a negative zeta potential of $-49.7 \pm 1.6 \mathrm{mV}$ that shifted toward neutral with increasing concentrations of the studied antiseptics (Table 1). That is most likely due to electrostatic binding of the cationic antiseptic molecules to the anionic lipids of the chromatophore membranes. At the same time phenoxyethanol did not affect the zeta potential of the chromatophores up to a concentration of $10 \mathrm{mM}$ (data not shown).

In the presence of chlorhexidine digluconate, picloxydine dihydrochloride, and miramistin in concentrations up to $100 \mu \mathrm{M}$, the absorbance spectra of chromatophores showed no pronounced changes in comparison with the control (data not shown). In the presence of octenidine in concentrations up to $40-50 \mu \mathrm{M}$, there was no noticeable drop in the extinction coefficient in the characteristic absorption bands of BChl: Soret-360-400 nm, $Q_{x}$-about $590 \mathrm{~nm}$, and $Q_{y}$ absorption bands of BChl molecules at 800,850 and $870 \mathrm{~nm}$. The absorbance spectrum of carotenoides in the range of 420-530 $\mathrm{nm}$ showed no changes as well (Fig. 2). Octenidine led to certain changes in the absorbance spectra of chromatophores only at concentrations $80-100 \mu \mathrm{M}$ and exposure times of more than $30 \mathrm{~min}$. Under these conditions, the decreased absorption in the $Q_{y}$ bands of $\mathrm{BChl}$ and the formation of a new wide absorption band in the range of $720-780 \mathrm{~nm}$ were registered (Fig. 2). The light scattering in the blue range also increased.

The most pronounced effect of octenidine was on the fluorescence spectra of chromatophores indicating a possible impairment of the efficiency of energy migration from LH2 to LH1. Thus, a gradual increase in the contribution of LH2 fluorescence $\left(\lambda_{\mathrm{fl}}=860 \mathrm{~nm}\right)$ to the integral luminescence and a slight decrease in the intensity of LH1 fluorescence $\left(\lambda_{\mathrm{fl}}=880 \mathrm{~nm}\right)$ are clearly observed with an increase in the concentration of octenidine (Fig. 3). In addition to the main fluorescence bands of the LH1 and LH2 complexes in the range of 820-950 nm, the appearance of a new fluorescence band near $720-820 \mathrm{~nm}$ could be detected with the concentrations of octenidine above $40-50 \mu \mathrm{M}$. The contribution of

Table 1 Zeta potential of $R b$. sphaeroides chromatophores at different concentrations of cationic antiseptics

\begin{tabular}{|c|c|c|c|c|}
\hline \multirow{2}{*}{$\begin{array}{l}\text { Concen- } \\
\text { tration } \\
(\mu \mathrm{M})\end{array}$} & \multicolumn{4}{|c|}{ Zeta potential $(\mathrm{mV})$} \\
\hline & Chlorhexidine & Picloxydine & Miramistin & Octenidine \\
\hline 5 & $-40.8 \pm 2.8$ & $-47.0 \pm 2.1$ & $-50.9 \pm 1.8$ & $-15.7 \pm 2.4$ \\
\hline 10 & $-37.8 \pm 2.6$ & $-36.7 \pm 3.2$ & $-38.5 \pm 1.4$ & $-8.7 \pm 1.2$ \\
\hline 50 & $-19.4 \pm 1.6$ & $-23.5 \pm 1.1$ & $-19.1 \pm 1.3$ & $-5.0 \pm 0.9$ \\
\hline 100 & $-2.1 \pm 0.7$ & $-6.6 \pm 1.2$ & $-2.9 \pm 0.8$ & $+5.8 \pm 4.7$ \\
\hline
\end{tabular}




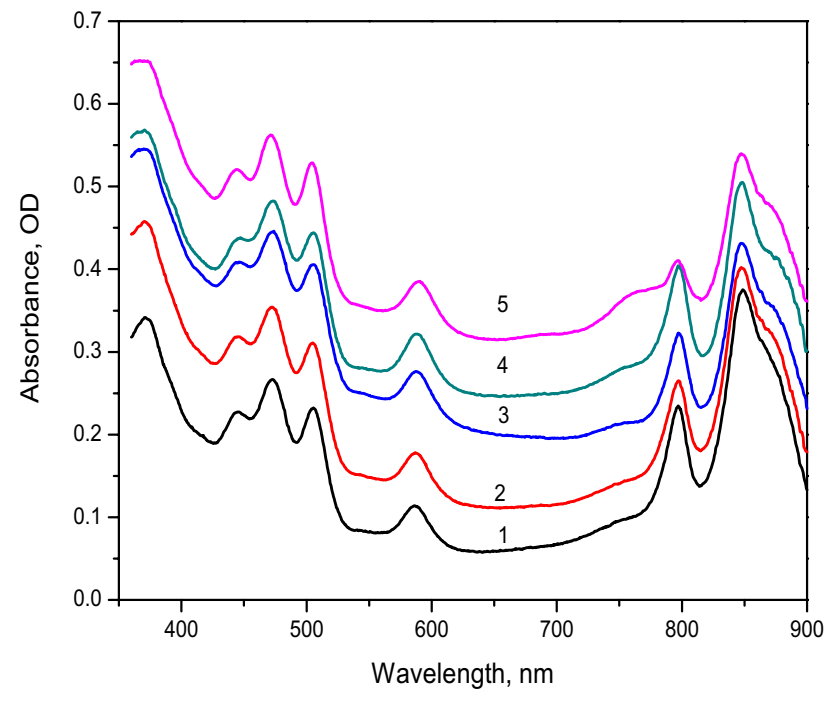

Fig. 2 Absorption spectra of $\mathrm{Rb}$. sphaeroides chromatophores: control sample (1) and after 5-min exposure with octenidine at a concentration of $20 \mu \mathrm{M}(2), 50 \mu \mathrm{M}(3), 100 \mu \mathrm{M}$ (4), and after 30-min exposure of chromatophores with $100 \mu \mathrm{M}$ of octenidine (5)

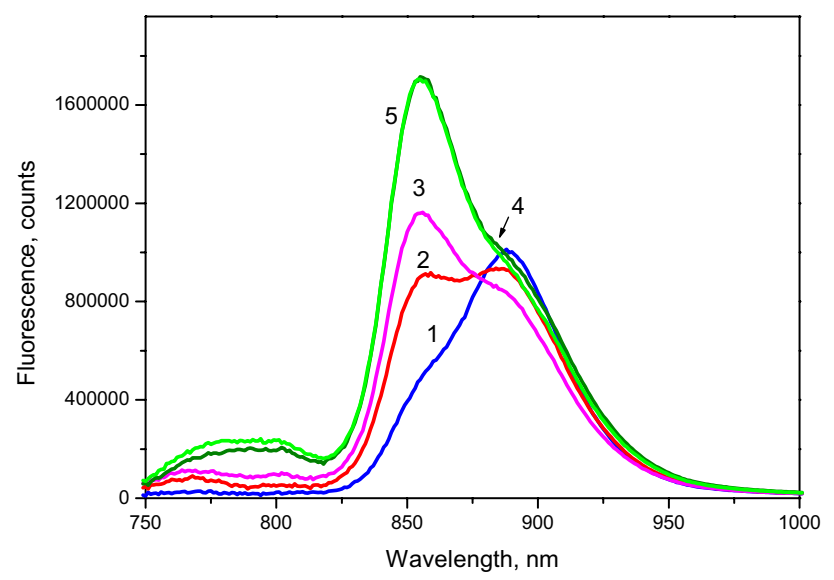

Fig. 3 Fluorescence spectra of $R b$. sphaeroides chromatophores: control sample (1) and samples with octenidine at concentrations of 30 (2), 50 (3), 80 (5), and $90 \mu \mathrm{M}$ (6). The optical density of the sample in the absorption band of $850 \mathrm{~nm}$ was about 0.15 . The time of incubation with octenidine was $10 \mathrm{~min} . \lambda_{\mathrm{ex}}=370 \mathrm{~nm}$

this band increased with increasing octenidine concentration (Fig. 3).

As it is seen from Fig. 4, a fluorescence maximum of about $772 \mathrm{~nm}$ appears in 5 min incubation of chromatophores with octenidine and it shifts to the longer wavelengths up to $786 \mathrm{~nm}$ after $30 \mathrm{~min}$ incubation (Fig. 4a). The observed decrease in the long-wave fluorescence of LH1 in the range of 870-950 $\mathrm{nm}$ reflects a decrease in the interaction between the LH2 and LH1 complexes during the time. Based on the changes in the fluorescence spectra of chromatophores with octenidine and the fluorescence excitation spectra of individual bands, the formation of both BPhe and free monomeric $\mathrm{BChl}$ may be supposed as a result of the antiseptic action (Fig. 4a). For comparison, the fluorescence spectrum of monomeric $\mathrm{BChl}$ obtained by adding ethanol to a chromatophore solution with the fluorescence maximum at $792 \mathrm{~nm}$ (Fig. 4a, curve 3) and the fluorescence spectrum of BPhe (Fig. 4a, curve 4) are given. To determine the position of the BPhe fluorescence band, we measured the fluorescence spectrum of pure reaction centers isolated from $\mathrm{Rb}$. sphaeroides chromatophores, when selectively excited in the BPhe $Q_{x}$ absorption band at $540 \mathrm{~nm}$. The fluorescence maximum of BPhe in $Q_{y}$ region appeared at $770 \mathrm{~nm}$, in the shorter wavelength range compared to the fluorescence band of the BChl monomer. Thus, the formation of BPhe occurs in a few minutes after addition of an antiseptic, but an extended time is required for the appearance of monomeric $\mathrm{BChl}$. The band at 750-820 $\mathrm{nm}$ in the fluorescence spectrum of chromatophores in the presence of octenidine is obviously a superposition of BPhe and monomeric BChl bands. This conclusion is confirmed by the fluorescence excitation spectra (Fig. 4b). The fluorescence excitation spectra of the LH1 complex (measured at $920 \mathrm{~nm}$ ) and the LH2 complex (measured at $845 \mathrm{~nm}$ ) with a Soret band of porphyrins at $360-400 \mathrm{~nm}, Q_{x}$ band of porphyrins at $590 \mathrm{~nm}$, and characteristic absorption bands of carotenoids at $450-520 \mathrm{~nm}$ were in general similar to the absorption spectrum of chromatophores. The smaller contribution of carotenoid bands in the fluorescence excitation spectrum compared to the absorption one reflects the fact that the efficiency of excitation energy migration from carotenoids to $\mathrm{BChl}$ is less than $100 \%$ and this efficiency is additionally slightly reduced when chromatophores are treated with octenidine. The fluorescence excitation spectrum detected at $780 \mathrm{~nm}$ in the range of 400-600 $\mathrm{nm}$ is principally different from the absorption spectrum: carotenoid bands are absent; $Q_{x}$ band of monomeric $\mathrm{BChl}$ with a maximum at $585 \mathrm{~nm}$ is shifted to shorter wavelengths and broadened. Especially it should be emphasized that a new band appears at $537 \mathrm{~nm}$ that is characteristic for BPhe absorption in solution, as well as a Soret band shifts to a new position, where both monomeric $\mathrm{BChl}$ and BPhe absorb. The absorption bands of BChl and BPhe in organic solvents (Reed and Peters 1972) coincide well with the peaks in the fluorescence excitation spectrum of chromatophores in the presence of octenidine (Fig. 4b).

What is the cause of the fluorescence bands of chromatophores in the spectral range of $720-820 \mathrm{~nm}$ characteristic of the BChl and BPhe molecules? Apparently, a certain structural disintegration of photosynthetic protein-pigment complexes occurs at high antiseptic concentrations with prolonged exposure when some $\mathrm{BChl}$ molecules lose the central magnesium atom to form BPhe, whereas part of them goes to the monomeric state. It is well known that the central $\mathrm{Mg}$ atom is rather weakly held in the porphyrin ring of 
Fig. 4 Fluorescence and fluorescence excitation spectra of $R b$. sphaeroides chromatophores: a fluorescence spectra of chromatophores in the presence of $100 \mu \mathrm{M}$ of octenidine after 5 min of exposure (1) and after $30 \mathrm{~min}$ of exposure (2). For normalization at $\lambda=860 \mathrm{~nm}$ the spectrum 2 is increased by 1.6 times. (3) The fluorescence spectrum of ethanol extract of BChl from chromatophores. (4) The fluorescence spectrum of bacteriopheophytin in reaction center preparations isolated from $R b$. sphaeroides chromatophores when selectively excited in the $Q_{x}$ bacteriopheophytin absorption band at $540 \mathrm{~nm}$. b Absorption (1) and fluorescence excitation (2-5) spectra of chromatophores for the emission of LH1 complexes at $920 \mathrm{~nm}$ in the control sample (2) and in the presence of $100 \mu \mathrm{M}$ octenidine (3), for the emission of LH2 complexes at $845 \mathrm{~nm}$ in the presence of $100 \mu \mathrm{M}$ octenidine (4), and fluorescence excitation spectrum of chromatophores with $100 \mu \mathrm{M}$ octenidine in the $780 \mathrm{~nm}$ band (5). The absorption spectrum (1) was added for comparison
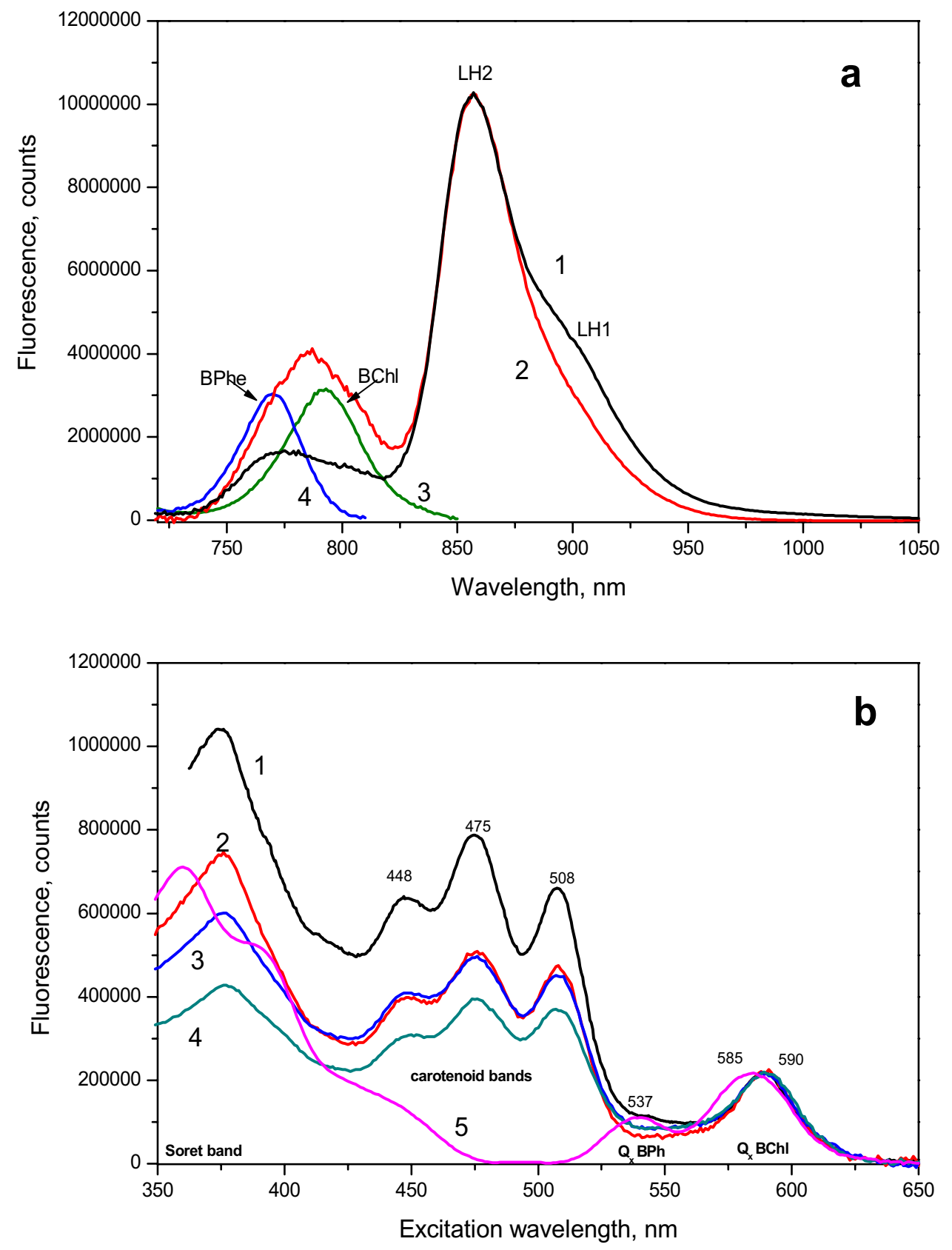

chlorophyll molecules and is easily replaced by two protons with the formation of pheophytin even with a small acidification of the medium (Joslin and Mackinney 1938). This may be the case with chlorine-containing antiseptics that locally acidify the medium. Despite the fact that the spectral characteristics of this minor porphyrin components of the photosynthetic membrane are characteristic of free BChl, the actual state of this free $\mathrm{BChl}$ molecules is unknown. It was shown (Hughes et al. 2006) that the absorbance spectrum of porphyrins is acutely sensitive to the protein environment, and it would take only very subtle alterations in the protein structure for dramatic spectral changes to occur.
When analyzing the fluorescence spectra of chromatophores in the presence of antiseptics, we proceeded from the fact that the fluorescence intensity of LH2 was inversely proportional to the efficiency of energy $\left(E_{\mathrm{eff}}\right)$ migration from $\mathrm{LH} 2$ to $\mathrm{LH} 1$. We used the ratio $\mathrm{FL}_{\mathrm{LH} 1} / \mathrm{FL}_{\mathrm{LH} 2}$ of the areas of the long-wavelength $\left(\mathrm{FL}_{\mathrm{LH} 1}\right)$ and short-wavelength $\left(\mathrm{FL}_{\mathrm{LH} 2}\right)$ components of the fluorescence spectrum decomposition as a characteristic of $E_{\text {eff. }}$ Figure 5a shows how the contributions to fluorescence from LH1 and LH2 change with increasing concentration of octenidine added to chromatophores. Figure 5b illustrates the effect of the antiseptics under study at a concentration of $100 \mu \mathrm{M}$ on the LH2 $\rightarrow \mathrm{LH} 1$ 

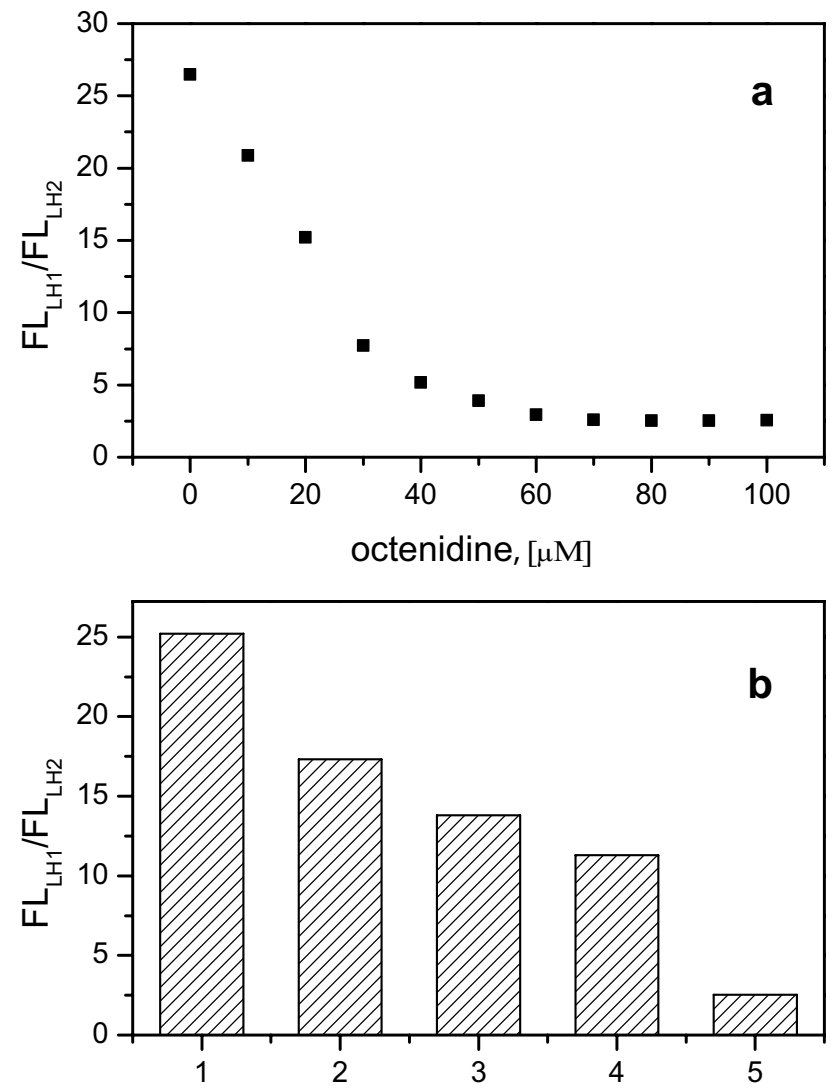

Fig. 5 a Ratio $\mathrm{FL}_{\mathrm{LH} 1} / \mathrm{FL}_{\mathrm{LH} 2}$ of the areas of the long- and shortwavelength components of the fluorescence spectrum decomposition before and after addition of octenidine at different concentrations; $\mathbf{b}$ effect of different antiseptics at a concentration of $100 \mu \mathrm{M}$ on the efficiency of energy migration LH2 $\rightarrow$ LH1: 1 -control, 2-miramistin, 3-chlorhexidine, 4-picloxydine, 5-octenidine. The error in the determining the values $\mathrm{FL}_{\mathrm{LH} 1}$ and $\mathrm{FL}_{\mathrm{LH} 2}$ was $\sim 5 \%$

energy transfer efficiency. The effect of antiseptics on the efficiency of energy transfer increases sequentially in a raw miramistin $\rightarrow$ chlorhexidine $\rightarrow$ picloxydine $\rightarrow$ octenidine. The energy transfer blocking effect of the antiseptics reached its maximum after about 10 min of incubation, after which it changed little.

The decomposition of the chromatophore fluorescence spectra into Gaussian components (Fig. 6) illustrates quantitatively the blocking of the $\mathrm{LH} 2 \rightarrow \mathrm{LH} 1$ transfer of light energy after adding $100 \mu \mathrm{M}$ octenidine and makes it possible to determine the dependence of the intensities of fluorescence of the LH1 and LH2 complexes and the fluorescence in the BPhe band on the octenidine concentration (Fig. 7). The fluorescence intensity was determined as the spectral area of the LH1, LH2 and BPhe fluorescence components. The fluorescence yield of LH1 virtually did not change with increasing octenidine concentration, while the fluorescence intensity of $\mathrm{LH} 2$ and BPhe increased by a factor of $\sim 15$ and $\sim 6$, respectively. Figure $7 \mathrm{~b}$ shows, in turn, a twofold increase in the intensity of the integral fluorescence of $(\mathrm{LH} 1+\mathrm{LH} 2)$ complexes with the addition of $80 \mu \mathrm{M}$ octenidine.

The fluorescence yield of LH1 did not change upon adding other antiseptics used in this work, while the fluorescence intensity of the LH2 complex increased to a lesser extent than in the case of octenidine (data not shown).

The disruption of the processes of energy migration from LH2 to LH1 in chromatophores with added antiseptics is also evidenced by the results of measurements of the sample fluorescence lifetimes. In these measurements, the direct electron transfer from the photoactive dimer BChl (P) to quinone acceptors was blocked, and the acceptors were restored in the dark by adding sodium dithionite $\left(10^{-2} \mathrm{M}\right)$ (Bernhardt and Trissl 2000). Accordingly, excitation of the samples by $80 \mathrm{MHz}$ light pulses after photo-separation of charges between $\mathrm{P}$ and the BPhe $\mathrm{RC}\left(\mathrm{H}_{\mathrm{A}}\right)$ led to dark recombination with a characteristic time of 2 ns under ordinary conditions: $\mathrm{P}^{+} \mathrm{H}_{\mathrm{A}}^{-} \rightarrow \mathrm{P}^{*} \mathrm{H}_{\mathrm{A}}$.

We recorded the fluorescence decay kinetics at $860 \mathrm{~nm}$ (LH2 fluorescence) and $890 \mathrm{~nm}$ (LH1 fluorescence) in control preparations of chromatophores and antiseptic-treated samples, and analyzed it using the bi-exponential approximation. The duration of the fast component in the control was found to be $220 \mathrm{ps}$, which is consistent with the data reported in Freiberg et al. (1996). We associated this component with the time of excitation migration from LH2 to LH1. The second, 800 ps component, is due to the fluorescence of "disconnected" LH2 light collectors that do not interact with the LH1 complexes (Freiberg et al. 1996). It should also be noted that, according to Freiberg and Timpmann (1992), the lifetime of fluorescence of disconnected LH1 and LH2 complexes is 700-900 ps, while, as reported in (Bergstrom et al. 1988), the lifetime of fluorescence of an isolated LH2 complex can reach $1.2 \mathrm{~ns}$.

The kinetics of chromatophore fluorescence decay was also measured after adding the antiseptic with the most pronounced effect, octenidine, in various concentrations (Table 2). As in the control preparations, the fluorescence kinetics was measured in the spectral ranges of LH2 $(860 \mathrm{~nm})$ and LH1 $(890 \mathrm{~nm})$ fluorescence. It can be seen from Table 2 that the lifetime of the fast component $\tau_{1}$ of the LH2 fluorescence kinetics gradually increases with increasing concentration of octenidine and reaches $630 \mathrm{ps}$ at the octenidine concentration of $100 \mu \mathrm{M}$. In our opinion, this increase in $\tau_{1}$ is due to a disruption of the interaction between the LH2 and LH1 complexes and the resulting decrease in the efficiency of the LH $2 \rightarrow$ LH1 energy migration. Under the same conditions, the duration of the second component of the LH2 fluorescence decay kinetics changes significantly less (by 20\%), remaining within the previously established range for isolated LH2: 700-1200 ps (Freiberg et al. 2012). 
Fig. 6 Decomposition into Gaussian bands (green curvefor LH2 and red curve-for LH1, blue curve-summarized spectrum) of the fluorescence spectra (black curve) the control chromatophores (a) and chromatophores with added $100 \mu \mathrm{M}$ octenidine (b)
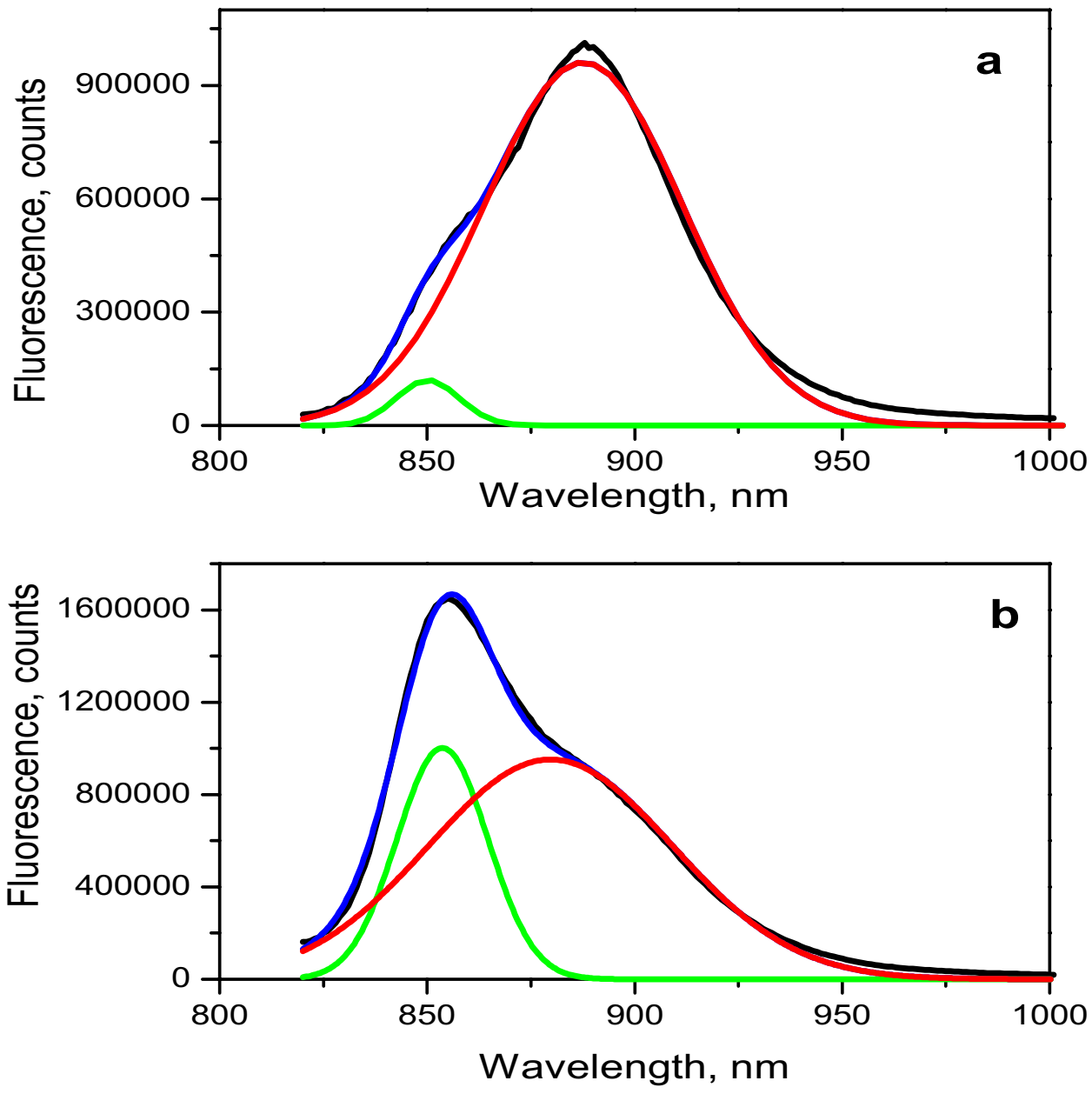

When analyzing the kinetics of fluorescence decay in the $890 \mathrm{~nm}$ band (fluorescence of the LH1 complex), we relied on the data presented in Fig. 7, according to which the LH1 fluorescence intensity does not change with the addition of an antiseptic. That is why, when approximating the kinetics of the fast component duration we used as a fixed parameter $\tau_{1}=110 \mathrm{ps}$, measured for the control sample. Therefore, the presence of octenidine in the medium does not affect the efficiency of the interaction of the LH1 antenna complex with the RC complex. At the same time, the lifetime of the second component $\tau_{2}$ increases with increasing octenidine concentration and, within the experimental error, coincides with the value of $\tau_{1}$ for the LH2 fluorescence decay kinetics (Table 2).

\section{Discussion}

In the purple bacteria $R b$. sphaeroides, the photosynthetic reaction center (RC) is surrounded by two light-harvesting complexes: LH1 and LH2. The pigment protein complexes of the $R b$. sphaeroides $\mathrm{RC}$ consist of three subunits with a total molecular weight of about 100,000 . These subunits include the following structural elements integrated into the protein matrix: the $\mathrm{BChl} \mathrm{P}$ dimer serving as the primary electron donor, two monomeric BChl molecules $\left(B_{\mathrm{A}}\right.$ and $B_{\mathrm{B}}$ ) localized, respectively, in the active (A) and inactive (B) electron transport chains, two BPhe molecules $\left(H_{\mathrm{A}}\right.$ and $\left.H_{\mathrm{B}}\right)$, and two molecules of quinone acceptors (ubiquinones -10 , $Q_{\mathrm{A}}$ and $Q_{\mathrm{B}}$ ). After photoactivation of the RC, the electron is transferred from the excited state of the primary donor $P^{*}$ (BChl dimer) to the BPhe molecule $\left(H_{\mathrm{A}}\right)$ over a period of 3-4 ps. After that, the electron passes within $200 \mathrm{ps}$ from $H_{\mathrm{A}}$ to the primary quinone acceptor $\left(Q_{\mathrm{A}}\right)$ molecule, and then, within 150-200 $\mu$ s, to the secondary quinone acceptor molecule. In preparations that do not contain external electron donors for photooxidizable $P$, the time of reoxidation in the dark to $P^{+}$is (provided that the next stage of direct transfer is blocked): $\sim 10 \mathrm{~ns}$ for the $P^{+}-H_{\mathrm{A}}{ }^{-}$recombination, $\sim 100 \mathrm{~ms}$ for the $P^{+}-Q_{\mathrm{A}}{ }^{-}$recombination, and $\sim 1$ s for the $P^{+}-\mathrm{Q}_{\mathrm{B}}{ }^{-}$recombination (Allen and Williams 1998; Hu et al. 2002).

In the photosynthetic membrane, RC and LH1 form a tightly bound LH1-RC complex in which each RC is surrounded by a ring structure of the LH1 complex containing 
Fig. 7 Dependence of the fluorescence intensity of the LH1, LH2 complexes and BPhe + BChl molecules (a) and the total integral fluorescence of the both LH1 and LH2 complexes (b) on the concentration of octenidine
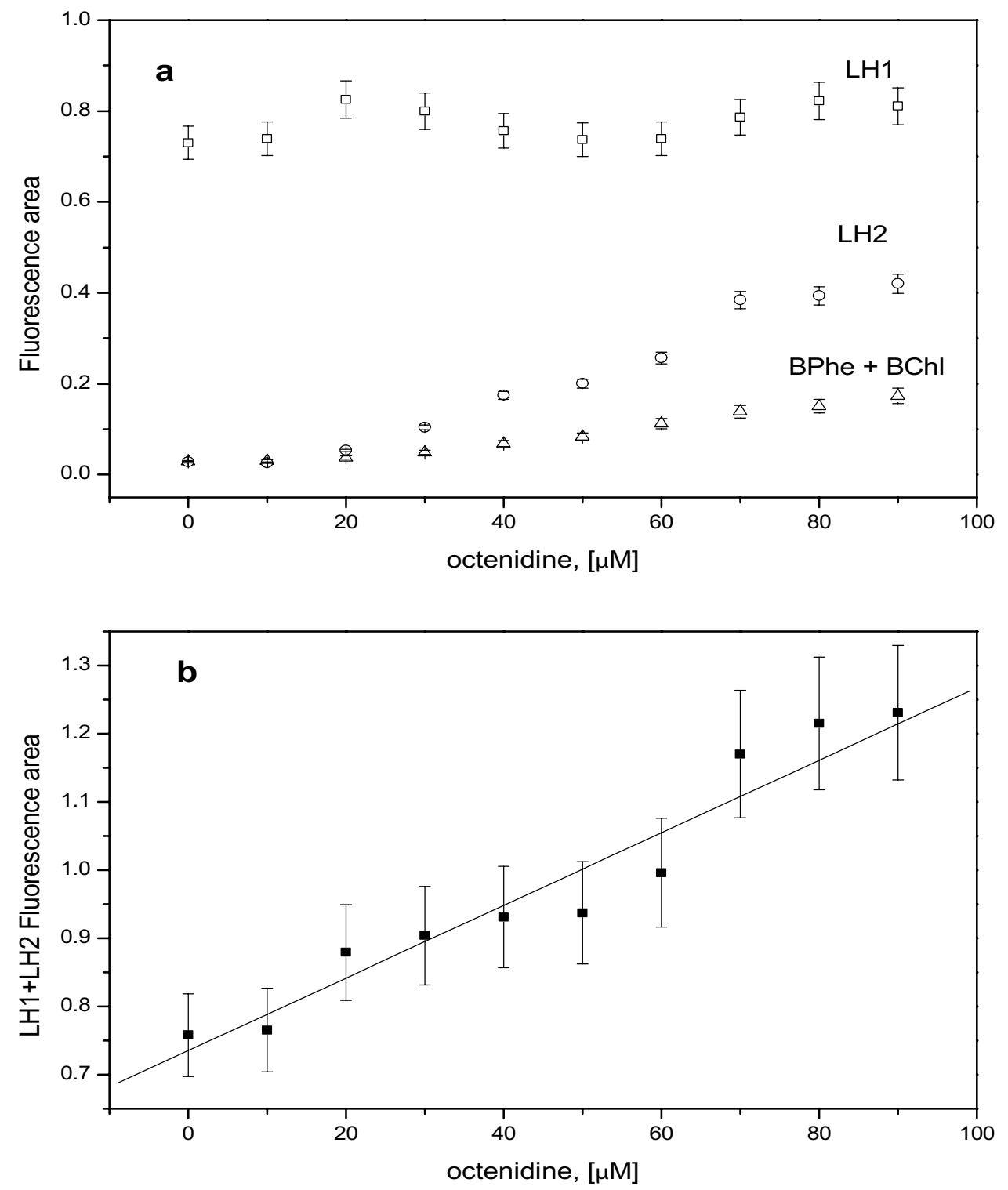

Table 2 Duration $\left(\tau_{1}, \tau_{2}\right)$ and amplitudes $\left(a_{1}, a_{2}\right)$ of the two components of the fluorescence kinetics of $R b$. sphaeroides chromatophores recorded at $\lambda=860 \mathrm{~nm}$ and $\lambda=890 \mathrm{~nm}$ and at different concentrations of added octenidine

\begin{tabular}{llllll}
\hline & Control & $10 \mu \mathrm{M}$ & $20 \mu \mathrm{M}$ & $50 \mu \mathrm{M}$ & $100 \mu \mathrm{M}$ \\
\hline $860 \mathrm{~nm}$ & & & & & \\
$\tau_{1}, \mathrm{ps}$ & 220 & 240 & 310 & 490 & 630 \\
$a_{1}$ & 0.81 & 0.8 & 0.76 & 0.65 & 0.61 \\
$\tau_{2}, \mathrm{ps}$ & 800 & 800 & 870 & 950 & 1080 \\
$a_{2}$ & 0.19 & 0.2 & 0.24 & 0.35 & 0.39 \\
$890 \mathrm{~nm}$ & & & & & \\
$\tau_{1}, \mathrm{ps}$ & 110 & 110 & 110 & 110 & 110 \\
$a_{1}$ & 0.69 & 0.72 & 0.73 & 0.83 & 0.86 \\
$\tau_{2}, \mathrm{ps}$ & 240 & 280 & 300 & 515 & 650 \\
$a_{2}$ & 0.31 & 0.28 & 0.27 & 0.17 & 0.14 \\
\hline
\end{tabular}

The accuracy of $\tau$ calculation was $\pm 10 \mathrm{ps}$
32 closely linked $\mathrm{BChl}$ molecules. The $Q_{y}$ absorption band of LH1 has a maximum at $875 \mathrm{~nm}$; the maximum of the fluorescence spectrum of this complex is concentrated at $885 \mathrm{~nm}$.

In contrast to LH1, the LH2 complex contains two spectrally different types of $\mathrm{BChl}$ molecules. The short-wavelength antenna is formed by $9 \mathrm{BChl}$ molecules absorbing at $800 \mathrm{~nm}$, while the remaining $18 \mathrm{BChl}$ molecules form a more closely linked structure absorbing at $850 \mathrm{~nm}$. Upon excitation, the energy from the ring of pigments forming the B800 complex is transferred very quickly to the ring of the B850 complex, which is capable of fluorescence. The maximum of the B850 fluorescence spectrum is concentrated at $860 \mathrm{~nm}$ (Sundström et al. 1999). There is always one LH1 complex per one RC (Roszak et al. 2003), whereas the number of LH2 complexes per RC is $4-6$ or more depending on 
the conditions of cell growth. According to X-ray structural data (McDermott et al. 1995; Koepke et al. 1996; Walz et al. 1998; Roszak et al. 2003; Olsen et al. 2008), the smallest distance between the $\mathrm{BChl}$ molecules of the neighboring LH1 and LH2 complexes is 22-24 $\mathrm{A}$ (Hu and Schulten 1998; Cogdell and Lindsay 2000).

The most important features of the organization of pigments in the photosynthetic membrane are the ring structure of $\mathrm{BChl}$ aggregates in individual pigment-protein complexes LH1 and LH2 and the coplanar arrangement of BChl molecules included in the structure of B850, B875, and RC. Moreover, each BChl molecule in the B850 and B875 circular aggregates is non-covalently bound to three atoms of the side chain of $\alpha$ and $\beta$ apoproteins, which rigidly fixes the orientation of the pigments ( $\mathrm{Hu}$ and Schulten 1998). Such structural organization provides a high efficiency of electron excitation energy migration $\mathrm{LH} 2 \rightarrow \mathrm{LH} 1 \rightarrow \mathrm{RC}$.

Fluorescence decay kinetics of chromatophores isolated from $R b$. sphaeroides cells grown under standard conditions usually contain three components with lifetimes of 100 , 200-300, and 700-1000 ps (Freiberg et al. 1996; Driscoll et al. 2014). In our opinion, the fast component with duration of $100 \mathrm{ps}$ is due to the capture of excitation energy from LH1, while the second component corresponds either to the energy migration from LH1 to LH2, or to the charge recombination $\mathrm{P}^{+} \mathrm{H}^{-}$. The third, long-lived component is due to the fluorescence of disconnected LH2 complexes that do not interact with LH1. It should be noted that the binding of LH2 complexes to LH1 determines both the fluorescence lifetime of LH2 and the efficiency of formation of exited states of LH1 complexes (Caycedo-Soler et al. 2011).

When approximating the fluorescence decay kinetics recorded in the spectral region of LH1 fluorescence $(890 \mathrm{~nm})$, we proceeded from the fact that the intensity of this fluorescence does not depend on the presence of octenidine. The value of $\tau_{1}=110 \mathrm{ps}$ was chosen as a fixed parameter for the kinetics decomposition into two exponentials for all octenidine concentrations. Such an approach is valid if we assume that octenidine does not affect the interaction between the LH1 and RC complexes.

In $R b$. sphaeroides chromatophores, phospholipids are concentrated inside the LH1 ring and densely fill the space between LH1 and RC, which facilitates the interaction between these two complexes (Nagatsuma et al. 2019). PG molecules are distributed between the periplasmic and cytoplasmic sides of the membrane, while the heads of all $\mathrm{CL}$ molecules are oriented towards the cytoplasmic side of the membrane. This, obviously, causes the high value of the negative zeta potential (about $-50 \mathrm{mV}$ ) of the chromatophores recorded in our experiments. The negative zeta potential is neutralized by adding cationic antiseptics in increasing concentrations, which is indicative of electrostatic binding of antiseptic molecules to the negatively charged surface of the chromatophores. The zeta potential was neutralized especially effectively by adding octenidine; at $100 \mu \mathrm{M}$ it even caused hyperpolarization of chromatophore membranes (see Table 1). It can be assumed that the concentration of negatively charged phospholipids on the outer (cytoplasmic) side of the chromatophore membrane leads to the binding of cationic antiseptic molecules and hinders their further penetration into the ring structure of LH1, thereby preventing an impairment of the effective interaction between LH1 and RC.

A completely different picture is observed when measuring the fluorescence decay kinetics of the LH2 antenna complex in the presence of antiseptic molecules (Table 2). With the addition of increasing concentrations of the most potent antiseptic agent, octenidine, $\tau_{1}$ gradually increases from 220 to $630 \mathrm{ps}$. The parameter $\tau_{2}$ of the LH1 fluorescence kinetics behaves in a similar way. Based on these data, we concluded that the component $\tau_{1}$ of the LH2 fluorescence kinetics and the component $\tau_{2}$ of the LH1 fluorescence kinetics reflect the LH2 $\rightarrow$ LH1 migration of the electron excitation energy. Thus, an increase in $\tau_{1}\left(\tau_{2}\right)$ from $220-240 \mathrm{ps}$ in the control samples to $630-650 \mathrm{ps}$ in the samples with added $100 \mu \mathrm{M}$ octenidine is due to a decrease in the efficiency of energy migration from the light-harvesting complex $\mathrm{LH} 2$ to the core complex LH1.

The amplitudes of the fast $\left(a_{1}\right)$ and slow $\left(a_{2}\right)$ components of the kinetics registered in the 860 and $890 \mathrm{~nm}$ bands are also shown in Table 2. It can be seen that as the concentration of octenidine increases, the amplitude of the fast component $a_{1}$ of the LH2 fluorescence $(860 \mathrm{~nm})$ decreases from 0.81 to 0.61 , and the $a_{1}$ value of the fluorescence kinetics in the $890 \mathrm{~nm}$ band (LH1) increases from 0.69 to 0.86 . This behavior of amplitudes is in full accordance with the assumption that in the presence of an antiseptic, the interaction between LH2 and LH1 complexes is disrupted, leading to a decrease in the effective energy migration from LH2 to LH1. The parameter describing the interaction of LH2 and LH1 is the rate constant of energy migration $\mathrm{LH} 2 \rightarrow \mathrm{k}_{\mathrm{m}} \rightarrow \mathrm{LH} 1$. It is easy to show that, for example, at an octenidine concentration of $100 \mu \mathrm{M}$, the efficiency of LH2-LH1 energy migration decreases by $\sim 9$ times. It is important to note that, based on the relative content of $\mathrm{BChl}$ molecules in the antenna complexes; we assumed that $~ 30 \%$ of the exciting light energy is directly absorbed by the LH1 antenna complex. It is for this reason that, despite a strong decrease in the share of energy entering LH1 from LH2, the amplitude of the fast component $\tau_{1}$ in the $890 \mathrm{~nm}$ band increases.

Table 2 also shows that the amplitude of the slow component $\mathrm{a}_{2}$ recorded in the $860 \mathrm{~nm}$ band increases from 0.19 to 0.39 . Hence, the contribution of the slow component $\tau_{2}$ actually increases only by $\sim 3$ times, whereas in steady state fluorescence measurements the intensity of the LH2 
spectrum is enhanced 15 times. For kinetic measurements, we estimate only the relative contributions of two components to the fluorescence decay kinetics. The real increase in the LH2 fluorescence yield is obtained from data on steady state measurements. In addition to an increase in the intensity of LH2 fluorescence due to a decrease of $k_{\mathrm{m}}$, the reason for its further increase may be the redistribution of constants of intramolecular deactivation of the excited BChl state in favor of $k_{\mathrm{fl}}$. This redistribution can occur, for example, as a result of changing the polarity of the $\mathrm{BChl}$ microenvironment when an antiseptic is added. This effect has been known for a long time. As follows, for example, from (Heath 1969), in nonpolar solvents, the deactivation of Chl* occurs due to $n-\pi^{*}$ transitions, and the fluorescence is very weak. In polar solvents, the main channel of $\mathrm{Chl}^{*}$ deactivation is the $\pi-\pi^{*}$ transition and the fluorescence yield is high. It is possible that the addition of antiseptics causes an increase in the polarity of the microenvironment of $\mathrm{BChl}$ molecules and leads to a significant increase in the fluorescence yield. Finally, the amplitude $\mathrm{a}_{2}$ of the slow kinetic component, registered in the $890 \mathrm{~nm}$ band decreases reflecting a decrease in the proportion of excitation energy entering LH1 from LH2. Within the experimental error the duration of this component $\tau_{2}$ is the same as the duration $\tau_{1}$ of the fast kinetics component recorded at $\lambda=860 \mathrm{~nm}$.

The efficiency of energy migration can be readily estimated using the following formula: $E_{\mathrm{eff}}=1-\tau_{\mathrm{da}} / \tau_{0}$, where $\tau_{0}$ and $\tau_{\mathrm{da}}$ are the donor fluorescence lifetimes in the absence and in the presence of the acceptor, respectively. Assuming that the lifetime of fluorescence of an isolated LH2 complex $\tau_{2}$ is approximately $1 \mathrm{~ns}$, it follows that $E_{\text {eff }} \approx 0.8$. Addition of $100 \mu \mathrm{M}$ octenidine results in $E_{\text {eff }} \approx 0.3$, which leads to a considerable increase in the LH2 fluorescence intensity (Fig. 6). The reason for this drop in $E_{\text {eff }}$ may be, for example, a slight increase in the distance between the ring aggregates $\mathrm{LH} 2$ and $\mathrm{LH} 1$. According to the results of our recent work (Kholina et al. 2020), this is quite realistic for a chromatophore membrane containing $42 \%$ of negatively charged lipids: PG + CL (Nagatsuma et al. 2019). The adsorption of the studied antiseptics and their effects on a number of parameters of a model membrane, in particular, on the degree of order of the acyl chains of lipids and on the amount of area occupied by the lipid in the membrane, was studied using MD methods (Kholina et al. 2020). The bacterial plasma membrane composed of PE and PG was simulated. The minimal disordering effect on the membrane was found for miramistin, due to the presence of only one charged group and long hydrophobic tail that fit well into the hydrophobic region of the membrane. Antiseptics with two positively charged groups had a greater disordering effect. Besides, antiseptics that possess shorter hydrophobic groups cannot penetrate as deep into the lipid bilayer as miramistin and, thus, they are not able to replace the lipid tails efficiently. Instead, being immersed in the headgroup region of membrane, they push lipids apart increasing the area per lipid and leading to the apparent decrease of the order parameter. Octenidine had the greatest disordering effect. Figure 8 shows the result of the adsorption of two of the four studied cationic antiseptics, miramistin and octenidine, on the surface of a model bacterial membrane, according to the work (Kholina et al. 2020). By impact efficiency on the parameters of the model membrane and the energy transfer in the chromatophore membrane, the studied cationic antiseptics are arranged in the same order.

Finally, as follows from Figs. 3 and $4 b$, the addition of octenidine leads to a significant increase in the fluorescence intensity at $750 \mathrm{~nm}$. A similar increase in the fluorescence at $750 \mathrm{~nm}$ was observed when adding other antiseptics (data not shown). This fluorescence band is attributed to the emission of monomeric BChl and BPhe. In our opinion, such an increase in the fluorescence intensity is due to an increase in the number of free BChl and BPhe molecules in the sample under the action of antiseptic molecules on $\mathrm{BChl}$ molecules of the light harvesting complexes. Interaction of octenidine with $\mathrm{BChl}$ can lead to pheophytinization of $\mathrm{BChl}$ molecules because of the removal of the $\mathrm{Mg}$ ion from these molecules. In this case, there should be a decrease in the relative content of BChl molecules in the light harvesting complexes, as well as an increase in the absorption (and fluorescence) in the BPhe band. Figures 3 and 4 show, this is actually the case. The appearance of monomeric Bchl and BPhe when exposed to antiseptics very likely occurs from a part of Bchl molecules of the LH2, namely B800, as it is seen from the absorption decrease in the B 800 band (Fig. 2). In the LH2 complexes, B800 molecules are localized near the cytoplasmic side of the chromatophore membrane and protrude from the protein (Ogren et al. 2018). For these reasons, B800 seems most vulnerable to the effects of antiseptics.

\section{Summary and concluding remarks}

In this work, we have presented the first results of an experimental study of the effect of some widely used cationic antiseptics molecules on the processes of energy migration from the light-harvesting complex LH2 to the core complex LH1-RC in chromatophores of $R b$. sphaeroides purple bacteria. In particular, it was found that the addition of $100 \mu \mathrm{M}$ octenidine leads to a significant (approximately three-fold) decrease in the efficiency of electronic excitation energy migration from LH2 to LH1-RC. As a result, the increase in the intensity of fluorescence in the band with the maximum at $860 \mathrm{~nm}$ is so conspicuous that the contribution of LH2 to the fluorescence spectrum of $R b$. sphaeroides chromatophores becomes predominant. At the same time, adding antiseptics at different concentrations does not affect the 


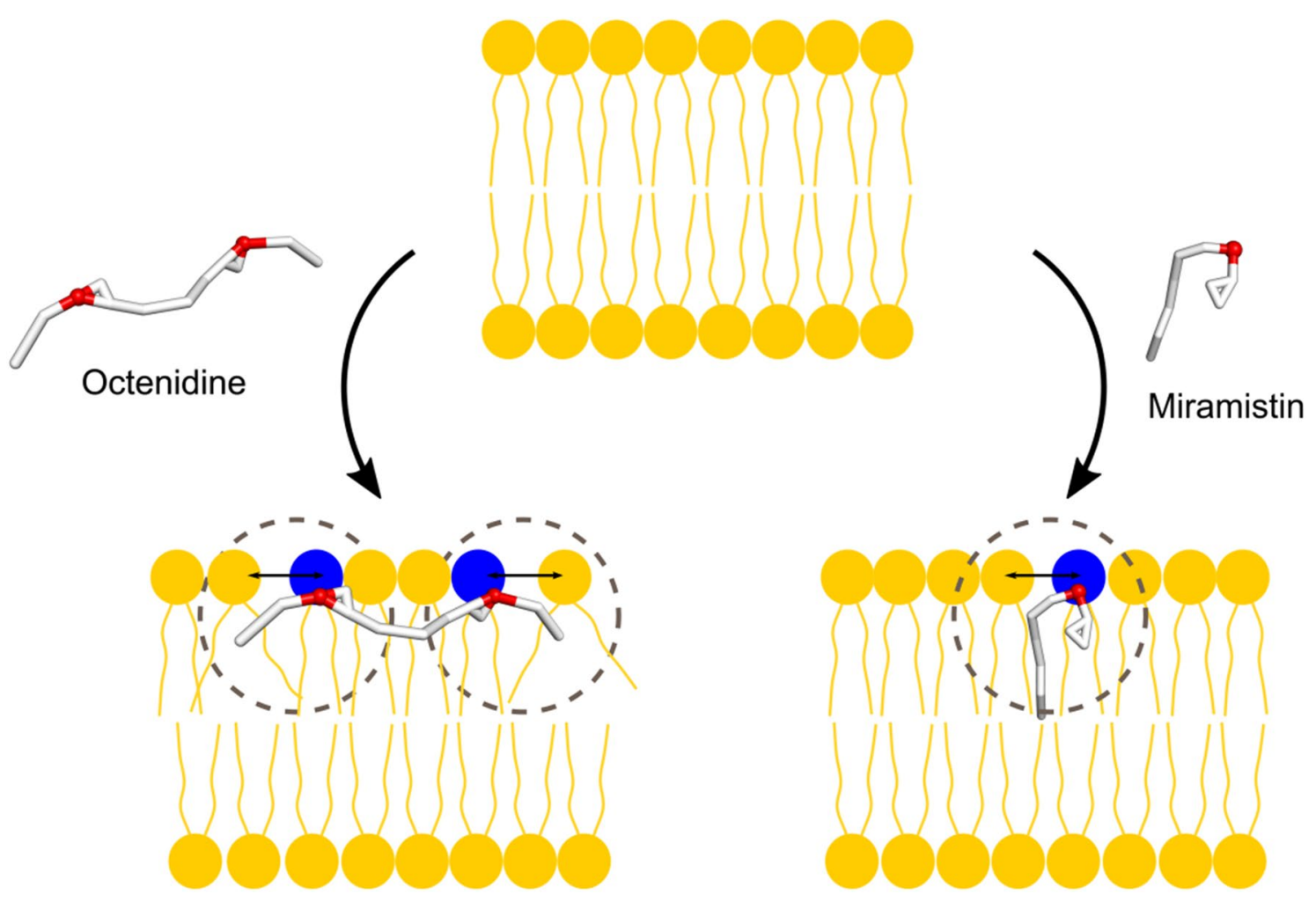

Fig. 8 Adsorption of cationic antiseptics octenidine and miramistin and their effects on the model bacterial membrane properties according to Kholina et al. (2020). Charged parts of antiseptic molecules are shown in red and negatively charged headgroups of anionic

intensity of fluorescence in the $890 \mathrm{~nm}$ band. In addition, the rate of energy migration from the $\mathrm{BChl}$ molecules of the LH1 antenna ring to the RC complex remains the same at all concentrations of antiseptics used in this work. These findings allow us to conclude that the addition of antiseptics does not affect the interaction of the LH1 complex with RC; however, it greatly reduces the interaction between the LH2 and LH1 complexes. The findings presented in this work are the first clear experimental data on the effect of antiseptics molecules on the efficiency of light energy conversion in the chromatophore membranes isolated from the photosynthetic bacterium $R b$. sphaeroides. Taking into account that there is no information about the effect of antiseptics on the energy migration and on the efficiency of interaction of antenna complexes in chromatophores of the purple bacterium $R b$. sphaeroides, we had to rely on a number of assumptions. In particular, we assumed that octenidine does not influence the interaction between LH1 and RC complexes. In addition, we supposed that fluorescence rate constant $\mathrm{k}_{\mathrm{ff}}$ in disconnected LH2 complexes increases significantly in the presence of antiseptics, especially octenidine due to the changing of polarity in the microenvironment of $\mathrm{BChl}$ molecules of $\mathrm{LH} 2$. At the same time, the lifetime of fluorescence of disconnected LH2 complexes varies slightly, within 800-1100 ps. lipids in bacterial membrane in blue. In the presence of octenidine, the increase of the area per lipid and the decrease of the lipid order parameter are schematically shown

Of course, such assumption requires experimental verification. Further studies in this direction should provide more detailed information about the mechanisms of the effect of such new (in terms of photosynthesis) agents on photosynthetic reactions.

Funding The reported study was funded by Russian Foundation for Basic Research (RFBR), Project Number 19-34-90045.

\section{Compliance with ethical standards}

Conflict of interest The authors declare no conflicts of interest.

\section{References}

Allen JP, Williams JC (1998) Photosynthetic reaction centers. FEBS Lett 438:5-9

Baker N, Williams AJ, Tropsha A, Ekins S (2020) Repurposing quaternary ammonium compounds as potential treatments for COVID19. Pharm Res 37:104

Bergstrom H, Sundstrom V, Vangrondelle R, Gillbro T, Cogdell R (1988) Energy transfer dynamics of isolated B800-850 and B800 820 pigment-protein complexes of Rhodobacter sphaeroides 
and Rhodopseudomonas acidophila. Biochim Biophys Acta 936:90-98

Bernhardt K, Trissl H-W (2000) Escape probability and trapping mechanism in purple bacteria: revisited. Biochim Biophys Acta 1457:1-17

Cartron ML, Olsena JD, Sener M, Jackson PJ, Brindley AA, Qiana P, Dickman MJ, Leggett GJ, Schulten K, Hunter CN (2014) Integration of energy and electron transfer processes in the photosynthetic membrane of Rhodobacter sphaeroides. Biochim Biophys Acta 1837:1769-1780

Caycedo-Soler F, Rodrigez FJ, Quiroga L, Zhao G, Johnson NF (2011) Energy conversion in purple bacteria photosynthesis. In: Photosynthesis. INTECH, London, pp 1-27

Cogdell RG, Lindsay JG (2000) The structure of photosynthetic complexes in bacteria and plants: an illustration of the importance of protein structure to the future development of plant science. New Phytol 145:167-196

Driscoll B, Lunceford C, Lin S, Woronowicz K, Niederman RA, Woodbury NW (2014) Energy transfer properties of Rhodobacter sphaeroides chromatophores during adaptation to low light intensity. Phys Chem Chem Phys 16:17133-17141

Escher BI, Hunziker RW, Schwarzenbach RP (2001) Interaction of phenolic uncouplers in binary mixtures: concentration-additive and synergistic effects. Environ Sci Technol 35:3905-3914

Freiberg A, Timpmann R (1992) Picosecond fluorescence spectroscopy of light-harvesting antenna complexes from Rhodospirillum rubrum in the 300-4 K temperature range. Comparison with the data on chromatophores. J Photochem Photobiol B Biol 15:151-158

Freiberg A, Allen JP, Williams JAC, Woodbury NW (1996) Energy trapping and detrapping by wild type and mutant reaction centers of purple non-sulfur bacteria. Photosyn Res 48:309-319

Freiberg A, Rätsep M, Timpmann K (2012) Comparative spectroscopic and kinetic study of photoexcitations in detergent-isolated and membrane-embedded LH2 light-harvesting complexes. Biochim Biophys Acta 1817:1471-1482

Goushcha AO, Manzo AJ, Scott GW, Christophorov LN, Knox PP, Barabash YuM, Kapustina MT, Berezetska NM, Kharkyanen VN (2003) Self-regulation phenomena applied to bacterial reaction centers 2. Nonequilibrium adiabatic potential: dark and light conformations revisited. Biophys J 84:1146-1160

Heath OVS (1969) The physiological aspects of photosynthesis. Stanford University Press, Stanford

Hu X, Ritz T, Damjanovic A, Autenrieth F, Schulten K (2002) Photosynthetic apparatus of purple bacteria. Q Rev Biophys 35:1-62

Hu X, Schulten K (1998) Model for the light harvesting complex I (B875) of Rhodobacter sphaeroides. Biophys J 75:683-694

Hughes AV, Rees P, Heathcote P, Jones MR (2006) Kinetic analysis of the thermal stability of the photosynthetic reaction center from Rhodobacter sphaeroides. Biophys J 90:4155-4166

Joslin MA, Mackinney G (1938) The rate of conversion of chlorophyll to pheophytin. J Am Chem Soc 60:1132-1136

Kasuno M, Kimura H, Yasutomo H, Torimura M, Murakami D, Tsukatani Y, Hanada S, Matsushita T, Tao H (2016) An evaluation of sensor performance for harmful compounds by using photoinduced electron transfer from photosynthetic membranes to electrodes. Sensors 16:438

Kholina EG, Kovalenko IB, Bozdaganyan ME, Strakhovskaya MG, Orekhov PS (2020) Cationic antiseptics facilitate pore formation in model bacterial membranes. J Phys Chem B 124:8593-8600

Knox PP, Churbanova IYu, Lukashev E, Zakharova NI, Rubin AB, Borissevitch GP (2000) Dipyridamole and its derivatives modify the kinetics of the electron transport in reaction centers from Rhodobacter sphaeroides. J Photochem Photobiol 56:68-77

Knox PP, Lukashev EP, Mamedov MD, Semenov AYu, Borissevitch GP (2001) Proton transfer in bacterial reaction centers and bacteriorhodopsin in the presence of dipyridamole. Prog React Kinet Mech 26:287-298

Knox PP, Lukashev EP, Simanova AV, Krupyanskii YuF, Loiko NG, El'Registan GI, Rubin AB (2010) The influence of alkylhydroxybenzenes on electron stabilization processes in the quinone acceptor portion of the reaction centers of the bacterium Rhodobacter sphaeroides. Microbiology 79:262-264

Kodama H, Hashimoto T, Tsuruoka M, Kido Y, Uyeda M, Shibata M (1988) Microbial degradation of disinfectants. IV. Treatment by activated sludge of chlorhexidine. Eisei Kagaku 34:408-413

Koepke J, Hu X, Munke C, Schulten K, Michel H (1996) The crystal structure of the light harvesting complex II (B800-850) from Rhodospirillum molischianum. Structure 4:581-597

Krasilnikov PM, Mamonov PA, Knox PP, Paschenko VZ, Rubin AB (2007) The influence of hydrogen bonds on electron transfer rate in photosynthetic RCs. Biochim Biophys Acta 1767:541-549

Kriegl JM, Forster FK, Nienhaus GU (2003) Charge recombination and protein dynamics in bacterial photosynthetic reaction centers entrapped in a sol-gel matrix. Biophys J 85:1851-1870

Liang C-M, Hung C-H, Hsu S-C, Yeh I-C (2009) Purple nonsulfur bacteria diversity in activated sludge and its potential phosphorus-accumulating ability under different cultivation conditions. Appl Microbiol Biotechnol 86:709-719

McDermott G, Prince S, Freer A, Hawthornwaite-Lawless A, Papiz M, Cogdell R, Isaacs N (1995) Crystal structure of an integral membrane light harvesting complex from purple bacteria. Nature 374:517-521

McEwan AG (1994) Photosynthetic electron transport and anaerobic metabolism in purple non-sulfur phototrophic bacteria. Antonie Van Leeuwenhoek 66:151-164

McMahon BH, Muller JD, Wraight CA, Nienhaus GU (1998) Electron transfer and protein dynamics in the photosynthetic reaction center. Biophys J 74:2567-2587

Michels PAM, Konings WN (1978) Structural and functional properties of chromatophores and membrane vesicles from Rhodopseudomonas sphaeroides. Biochim Biophys Acta 507:353-368

Nagatsuma S, Gotou K, Yamashita T, Yu L-J, Shen J-R, Madigan MT, Kimura Y, Wang-Otomo Z-Y (2019) Phospholipid distributions in purple phototrophic bacteria and LH1-RC core complexes. Biochim Biophys Acta 1860:461-468

Ogren JI, Tong AL, Gordon SC, Chenu A, Lu Y, Blankenship RE, Cao J, Schlau-Cohen GS (2018) Impact of the lipid bilayer on energy transfer kinetics in the photosynthetic protein LH2. Chem Sci 9:3095-3104

Okubo Y, Futamata H, Hiraishi A (2006) Characterization of phototrophic nonsulfur bacteria forming colored microbial mats in a swine wastewater ditch. Appl Environ Microbiol 72:6225-6233

Olsen JD, Tucker JD, Timney JA, Qian P, Vassilev C, Hunter CN (2008) The organization of LH2 complexes in membranes from Rhodobacter sphaeroides. J Biol Chem 283:30772-30779

Opatz T, Senn-Bilfinger J, Richert C (2020) Thoughts on what chemists can contribute to fighting SARS-CoV-2-a short note on hand sanitizers, drug candidates and outreach. Angew Chem Int Ed Engl 59:9236-9240

Pimenova MN, Grechushkina NN, Azova LG, Semenova EV, Myl'nikova SI (1983) Practical handbook of microbiology. MGU Publishers, Moscow (in Russian)

Reed DW, Peters GA (1972) Characterization of the pigments in reaction center preparations from Rhodopseudomonas sphaeroides. J Biol Chem 247:7148-7152

Roszak AW, Howard TD, Southall J, Gardiner AT, Law CJ, Isaacs NW, Cogdell RG (2003) Crystal structure of the RC-LH1 core complex from Rhodopseudomonas palustris. Science 302(5652):1969-1972 
Sener MK, Olsen JD, Hunter CN, Schulten K (2007) Atomic-level structural and functional model of bacterial photosynthetic membrane vesicle. Proc Natl Acad Sci USA 104:15723-15728

Sundström V, Pullerits T, van Grondelle R (1999) Photosynthetic lightharvesting: reconciling dynamics and structure of purple bacterial LH2 reveals function of photosynthetic unit. J Phys Chem B 103:2327-2346

Trissl HW, Law CJ, Cogdell RJ (1999) Uphill energy transfer in LH2containing purple bacteria at room temperature. Biochim Biophys Acta 1412:149-172

Walz T, Jamieson SJ, Bowers CM, Bullough PA, Hunter CN (1998) Projection structures of three photosynthetic complexes from
Rhodobacter sphaeroides: LH2 at $6 \AA$, LH1 and RC-LH1 at 25 Á. J Mol Biol 282:833-845

Wei H, Okunishi S, Yoshikawa T, Kamei Y, Maeda H (2016) Isolation and characterization of a purple non-sulfur photosynthetic bacterium Rhodopseudomonas faecalis strain A from swine sewage wastewater. Biocontrol Sci 21:29-36

Publisher's Note Springer Nature remains neutral with regard to jurisdictional claims in published maps and institutional affiliations. 